\title{
HAEMOGLOBIN POLYMORPHISM IN INDIAN ZEBU CATTLE
}

\author{
S. N. NAIK, P. K. SUKUMARAN and L. D. SANGHVI \\ Cancer Research Institute, Tata Memorial Centre, Bombay, India
}

Received 6.vi.68

\section{Introduction}

HAEMOGLOBIN polymorphism was first reported in cattle by Cabannes and Serain (1957) in Algerian hill cattle. Two haemoglobins, $H b-A$ and $H b-B$, and three phenotypes, $H b-A A, H b-A B$ and $H b-B B$ were shown to be the products of a pair of co-dominant alleles, with $H b-B$ having a faster electrophoretic mobility than $H b-A$ in an alkaline buffer system (Bangham, 1957; Grimes et al., 1957; Salisbury and Shreffler, 1957). Lehmann (1959) reported the presence of $H b-A$ and $H b-B$ in the Indian Gir cattle. The third haemoglobin $(H b-X)$, with a mobility intermediate between those of $H b-A$ and $H b-B$, and different from the foetal type, was first found by Naik et al. (1962, 1965). A haemoglobin variant called $H b-C$ with an electrophoretic mobility similar to $H b-X$ was reported by Crockett et al. (1963) in American Brahmin cattle. Naik and Sanghvi (1964) reported the fourth adult haemoglobin, called $\mathrm{Hb}$-Khillari, in Indian cattle, with a mobility slower than that of $H b-A$. Efremov and Braend (1965) reported still another haemoglobin which was also slower than $H b-A$ like $H b$-Khillari, in Muturu cattle from Africa. The discovery of these haemoglobin variants in zebu cattle of Indian and African origin prompted us to screen a large number of Indian zebu cattle of different breeds for their haemoglobin variants. In this paper we attempt to present the data of this survey together with those of the Western cattle breeds studied in our laboratory.

\section{Materials AND METHODS}

Blood samples were aseptically collected in citrate saline from carefully selected, adult, healthy, unrelated animals belonging to different recognised Indian cattle breeds. Blood samples from the adult healthy hill cattle from Kumaon, near the Himalayas, were received by the courtesy of the Heads of the Genetics and Pathology Divisions of the Indian Veterinary Research Institute, Izatnagar. In all 2158 blood samples belonging to different breeds, viz., Malvi (302); Khillari (328); Kankrej (343); Dangi (333); Gir (404); Rathi (278); and Kumaon hill cattle (170) were analysed for their haemoglobin variants. Ninety-one blood samples from the Jersey cattle imported from U.S.A., 50 from Bohemian Red Spotted cattle and 40 from Finland cattle were also included in this study for the sake of comparison.

The red blood cells were washed with saline to free them from plasma proteins, and then lysed with an equal volume of distilled water. The haemolysates were mixed with one-quarter volume of toluene and left at $-20^{\circ} \mathrm{C}$. overnight. The next day the samples were thawed and centrifuged 
at 3000-4000 r.p.m. for half an hour, when clear haemoglobin solution was separated free from coagulated stroma proteins and toluene. The haemoglobin concentration was adjusted to $10 \mathrm{~g}$. per cent. with distilled water and the solutions were preserved as carboxy-haemoglobin prior to electrophoresis. For the estimation of alkali-resistant haemoglobin, however, oxy-haemoglobin was used.

Electrophoretic runs were made at $20-25^{\circ} \mathrm{C}$. for $10-12$ hours at 200 volts and $3 \mathrm{~mA}$ per strip of $8.7 \mathrm{~cm} . \times 36.5 \mathrm{~cm}$. of Whatman No. 3 filter paper using veronal buffer of $p \mathrm{H} 8.6$ with an ionic strength of 0.05 . Since haemoglobin is a coloured protein, the results were read directly. Samples with ambiguous results were re-run to confirm their phenotypes.

\section{Results}

Table 1 summarises the total number of animals examined and the percentage of haemoglobin variants together with their gene frequencies in Indian and Western cattle breeds. The two common haemoglobins, $H b-A$ and $H b-B$, were found in three phenotypes, viz., $H b-A A, H b-A B$, and $H b-B B$ (plate $\mathrm{I} a$ ). The $H b-A$ and $H b-B$ from Indian cattle were found to have similar electrophoretic mobility to those from Western cattle under our experimental conditions.

Among 2158 animals belonging to 7 different Indian cattle breeds examined, 18 animals revealed a third haemoglobin variant, called $H b-X$, which had an electrophoretic mobility between $H b-A$ and $H b-B$ (plate I $a$ ). This variant, however, had distinctly slower mobility than that of the $H b-F$ (plate $\mathbf{I} b$ ). The rest of the animals examined, excepting the one Khillari animal, were either homozygous for $H b-A$ or $H b-B$, or heterozygous for $H b-A B$ types. The $H b-X$ was in every case found associated either with $H b-A$ or $H b-B$; the homozygous type, $H b-X X$ was not observed in the course of this survey. In addition, a single animal was found with a combination of $H b-A$ and a different variant, with a mobility slower than that of $H b-A$. As this animal belonged to the Khillari breed, the variant was tentatively named $H b$-Khillari.

From among the Western cattle studied, only the Jersey animals from U.S.A. showed all the three common phenotypes, $H b-A, H b-A B$, and $H b-B$; the Bohemian Red Spotted cattle had $H b-A$, and $H b-A B$ types, while the Finnish cattle were all homozygous for $H b-A$ type. None of them showed rare variants, either $H b-X$ or $H b$-Khillari.

The distribution of the haemoglobin phenotypes in Indian and Western cattle are shown in the histogram (fig. 1). The animals with $H b-X$ and $H b$-Khillari variants were not included in the histogram.

The $H b-A A$ type did not differ much in frequency among Malvi, Khillari, Dangi and Gir breeds. It varied from 25.83 per cent. in Dangi to 28.80 per cent. in Malvi. The Kankrej and Rathi breeds showed much higher frequencies, 34.11 per cent. and 32.01 per cent. respectively, than the Dangi breed, though the differences were statistically not significant. The hill cattle showed 52.94 per cent. for $H b-A A$ type, the highest frequency among the Indian cattle breeds.

The Western cattle showed $H b-A A$ frequencies which varied from 32.97 per cent. in Jerseys, which is comparable to that of Rathi and Kankrej, to 100 per cent. in the Finnish cattle. The Bohemian Red Spotted cattle 
HAEMOGLOBINS OF ZEBU CATTLE

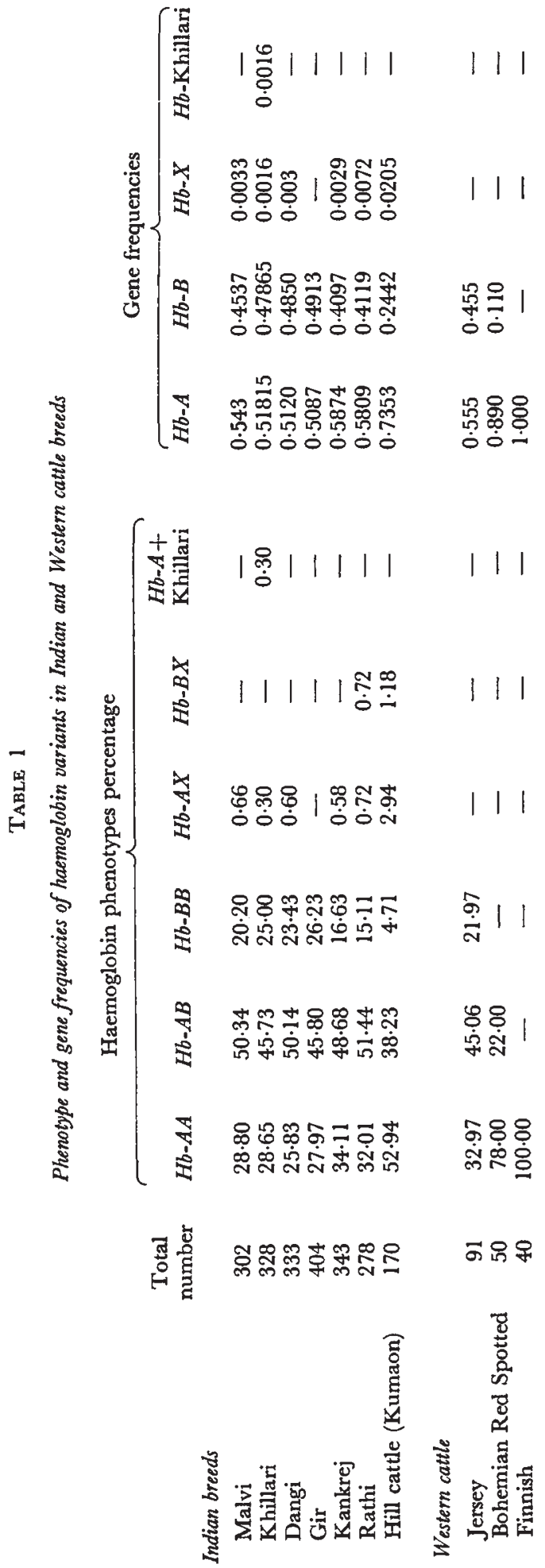


had 78 per cent. $H b-A A$ type which was about two and a half times that in the Jersey cattle.

The common heterozygous phenotype $H b-A B$ had very little variation in its frequency among the Indian cattle breeds from the plain. It varied from 45.73 per cent. in Khillari to 51.44 per cent. in Rathi breed. The only Indian breed which showed significant difference in its frequency was that of the Kumaon hill cattle, which had 38.23 per cent. Among the Western cattle, Jerseys had 45.05 per cent. which was almost equal to the frequencies found in some of the Indian breeds. The Bohemian Red Spotted cattle had only 22 per cent. of $H b-A B$ type. The Finnish cattle, however, failed to reveal any of the $H b-A B$ type from 40 animals examined.

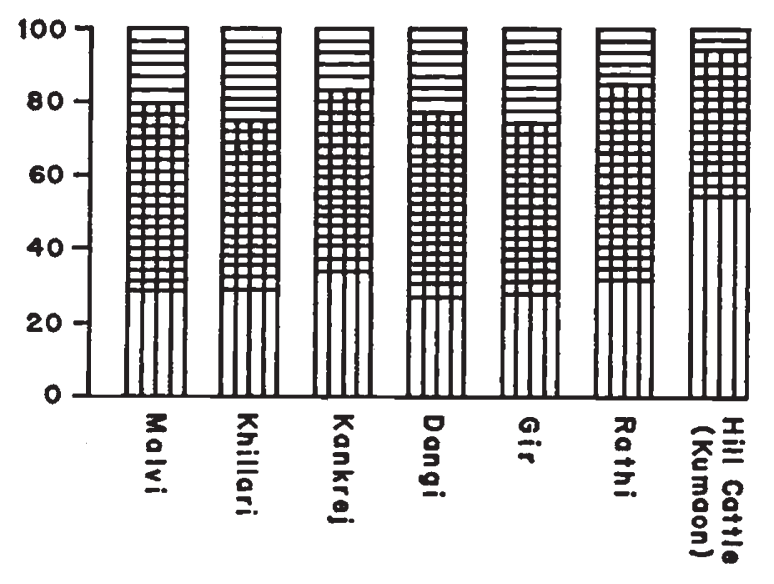

- IN DIA
$-1$

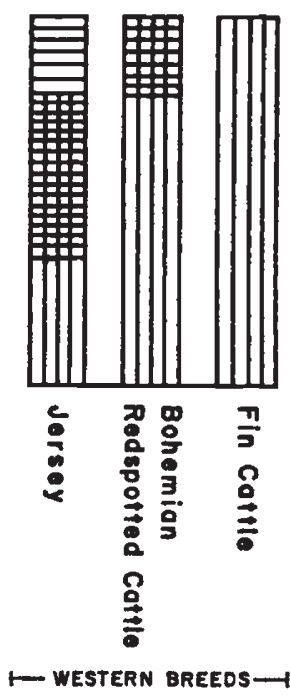

$\mathrm{Hb}, \mathrm{BB}$

Frg. 1.-Distribution of haemoglobin phenotypes in cattle breeds.

The $H b-B$ did not show any considerable differences in its percentage frequencies between Malvi, Khillari, Dangi and Gir breeds. The Kankrej and the Rathi breeds showed significantly low frequencies, 16.63 per cent. and 15.11 per cent. respectively. The Kumaon hill cattle showed a highly significant low frequency which was only 4.71 per cent. The Jerseys, the only Western cattle which had homozygous $H b-B$ type, had a frequency of 21.97 per cent., which was similar to that of many of the Indian breeds studied.

The $H b-X$, though a rare variant, was found in all the Indian breeds except the Gir, which even after screening 404 animals did not reveal $H b-X$. There was one animal with $H b-X$ variant in Khillari, while the Malvi, Kankrej and Dangi had each two animals with $H b-X$. These breeds had $H b-X$ along with $H b-A$ only. The frequency of $H b-X$ in the Rathi and the hill cattle was significantly higher than that in the other Indian breeds. There were 4 out of 278 animals in the Rathi and 7 out of 170 animals among the hill cattle which revealed $H b-X$ in association either with $H b-A$ 
or $H b-B$. On the whole, the phenotype $H b-A X$ was found to be commoner (14 cases) than $H b-B X$ (4 cases). We have not yet found an example of the $H b-X X$ phenotype in any of the cattle breeds surveyed so far, and it must be very rare indeed.

The one out of 328 animals of the Khillari breed exhibited an extremely rare haemoglobin variant called $H b$-Khillari in association with $H b-A$. This variant was not found in any other breed studied. The other expected combinations of this variant were not found during this study.

\section{INHERITANCE}

$H b-A$ and $H b-B$ are known to be determined by two allelic genes with no dominance (Grimes et al., 1957; Bangham, 1957; Shreffler and Salisbury, 1959; Naik et al., 1965). Crocket et al. (1963) reported that $H b-X$ is determined by a gene allelic with $H b-A$ and with no dominance. We also have evidence to show that $H b-B$ and $H b-X$ segregate independently. A Rathi dam with $H b-B X$, when mated to a sire having $H b-A A$, gave birth to an offspring with $H b-A B$. The same dam when mated to another sire ( $H b$ type not known) the next year gave birth to another calf with $H b-B X$. These two matings show that the $H b-B$ and $H b-X$ segregate independently of each other. It was also observed that the heterozygous phenotypes, viz., $H b-A X$ and $H b-B X$, like the $H b-A B$, had an equal concentration of both of their component haemoglobins (plate $\mathrm{I} a$ ). Further observations with planned matings is in progress to study the exact mode of inheritance of $H b-X$.

The only animal with $H b$-Khillari was a bullock and therefore its inheritance could not be studied. The heterozygous propositus, however, showed an equal concentration of $H b-A$ and $H b$-Khillari, like $H b-A$ and $H b-B$ in the $H b-A B$ type.

\section{Discussion}

Breed differences in the frequency of haemoglobin variants have been reported by several workers already cited. Most of the Western cattle breeds are known to have only $H b-A$ (Ogden, 1961), while a few present $H b-B$ as well as $H b-A$ (Kiddy, 1964).

The present study revealed four haemoglobin variants, viz., $H b-A, H b-B$, $H b-X$ and $H b$-Khillari in Indian cattle breeds. The gene frequencies of $H b-A$ and $H b-B$ in Malvi, Khillari, Dangi and Gir breeds were almost equal, while in Kankrej, Rathi and hill cattle, the $H b-A$ gene was found in excess over $H b-B$. Thus the animals on the central and western plains (fig. 2), which have an equitable climate and heavy rainfall, showed almost an equal distribution of $H b-A$ and $H b-B$ genes. The Kankrej from North Gujarat and the Rathi from Rajastan, both from arid zones, showed a gradual increase in $H b-A$ gene frequency. Balakrishnan and Nair (1966) and Sen et al. (1966) also reported a higher gene frequency of $H b-A$ than of $H b-B$ in Red Sindhi, Tharparkar and Sahiwal, all of which belong to the northern arid regions. The hill cattle from the Kumaon Hills, at the foot of the Himalayas, also showed very striking increase in $H b-A$ gene frequency $(0.7353)$. Thus as we go away from the equator, and with the prevalence of extremes of weather, the frequency of $H b-A$ seemed to increase over that of $H b-B$. Further haemoglobin studies in cattle from southern India might 
explain the geographical influence upon the distribution of the haemoglobin variants. It is worth considering whether the decrease of $H b-B$ in the Kankrej, Rathi and hill cattle breeds is related to tolerance of trypanosomiasis, as suggested by Bangham and Blumberg (1958). Lehmann and Ross (1961) failed to demonstrate any mechanism of balanced polymorphism

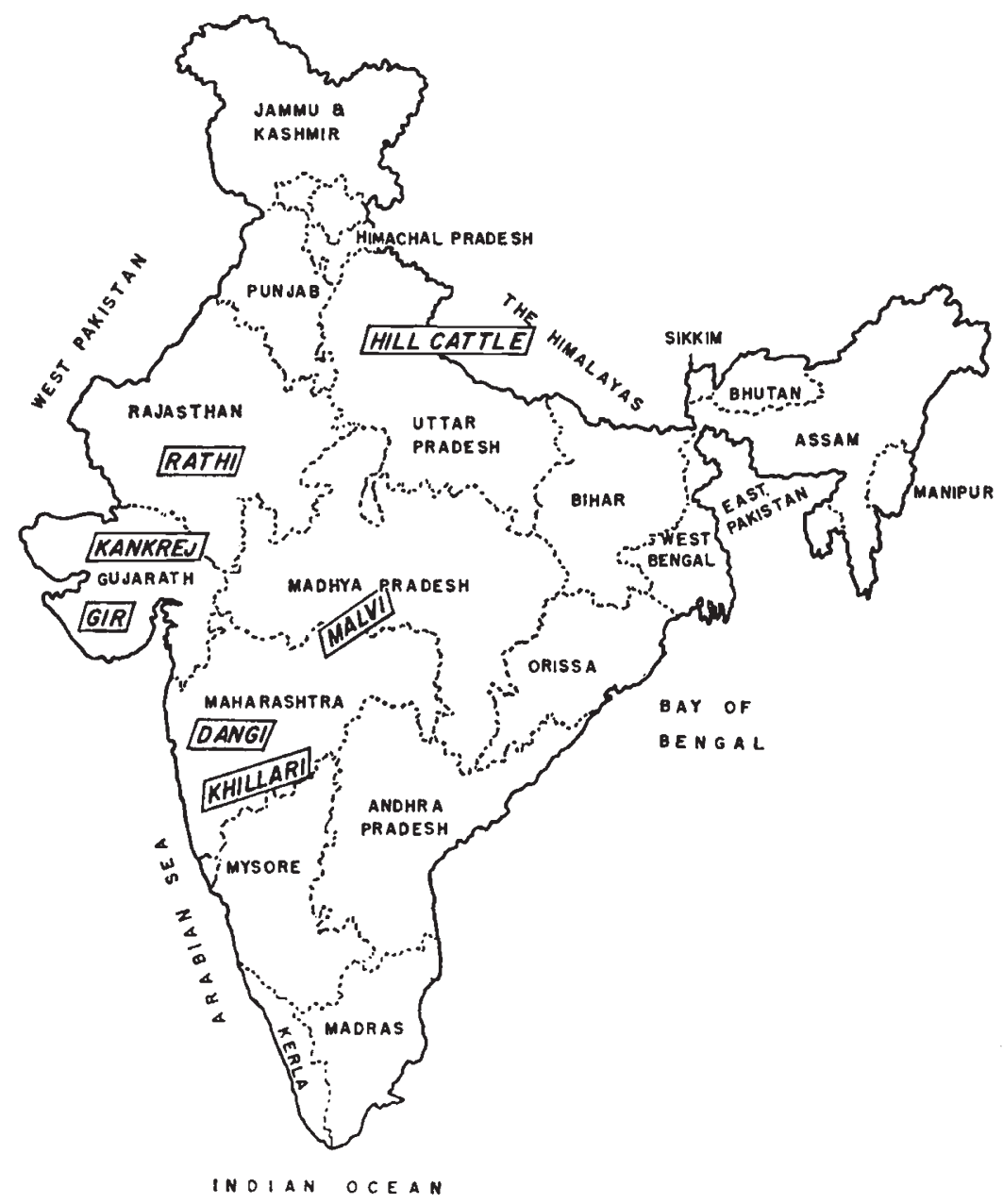

Fig. 2.-Map of India showing the habitat of seven cattle breeds.

for the cattle haemoglobins, such as had been found for the human haemoglobins by Allison (1954) in relation to malarial infection. However, the report of Evans et al. (1957) regarding the physiological adaptive role of haemoglobin variants in the British breeds of sheep, gives encouragement to further investigations on cattle. The advantages enjoyed by the heterozygotes over either of the homozygotes were not yet clear from our studies though all breeds excepting the hill cattle showed that about 50 per cent. of each population was of the $H b-A B$ type.

The third haemoglobin, $H b-X$, was discovered by us in Indian cattle from the plains in 1959. On account of its very low frequency it was 
presumed that $H b-X$ might be a mutated haemoglobin like $H b-S$ in man, selected because of some advantage it conferred in the adverse environment, and that it might thus occur in higher frequency in the hill cattle. It was, therefore, arranged to procure 170 blood samples from the hill cattle to study their haemoglobin variants. The study revealed a high frequency of $H b-X(0.0205)$ when compared to the rest of the breeds (see table 1 ).

The $H b-X$ was found to be readily distinguishable from the foetal type. The age of the animals which revealed $H b-X$ varied from 1 to 6 years and no foetal fraction was noticed beyond 39 days of age in Indian calves. No striking difference in the quantity of alkali-resistant fraction in $H b-A B$, $H b-A X$ and $H b-B X$ was noticed, as would be expected for foetal haemoglobin. Besides this criterion, the slightly faster mobility of the foetal component than that of $H b-X$ clearly shows difference in their physicochemical properties (plate $\mathrm{I} b$ ). In this connection it is interesting to note the experimental work on sheep by Moore et al. (1966), where they succeeded in producing $H b-C$ in sheep homozygous for $H b-A$ by creating severe blood loss anaemia due to phelobotomy. With this in mind, attempts were made, by haematological examination, to ascertain whether any of the animals with rare variants like $H b-X$ show indications of a haemolytic process. These did not reveal anaemia or difference in cell morphology such as are seen in human haemoglobinopathies. If these variants result from defective synthesis of polypeptide chains, as in the case of human haemoglobin variants, the amount of the abnormal fraction should be lower than that of the normal ones. As already mentioned, this is not revealed for any of the new variants encountered in our study. Besides, $H b-X$, which has a similar electrophoretic mobility to $H b-C$, was also not found to be lethal in association with $H b-B$ as was suspected by Crockett et al. (1963). The higher incidence of $\mathrm{Hb}-\mathrm{X}$ noticed in the hill cattle invites further work to elucidate whether it affords any advantage to the animal in its adverse environment, like $H b-S$ in man.

The demonstration of a rare haemoglobin like $H b-X$ in the Kumaon hill cattle and 5 of the 6 other Indian breeds studied proves the possibility of their common ancestry. The absence of $H b-X$ in Gir cattle, even after examining 404 animals, could be due to their origin from a different stock as suggested by Balakrishnan and Nair (1966), who studied 53 Red Sindhi, 170 Sahiwal, and 232 Tharparker in Punjab and did not encounter either $H b-X$ or $H b$-Khillari. So also Sen et al. (1966) studied 102 Hariana, 100 Desi, 44 Sahiwal, 29 Gir, 25 Tharparker and 17 Red Sindhi in West Bengal and could not find either of the rare variants in them. If these findings are substantiated by further study of large number of samples, it should be possible to assign the probable stocks of origin of Indian cattle breeds. The prevalence of $H b-X$ in 6 out of 7 Indian breeds and in American Brahmin cattle with zebu ancestry (Crockett et al., 1963) and also in African zebu cattle (Carr, 1965), and the absence of any report on its occurrence in Western cattle, should be of value, in conjunction with the varying incidences of $\mathrm{Hb}-\mathrm{B}$, in tracing the origins of the various breeds (Bangham and Blumberg, 1958). If $H b-X$ and $H b$-Khillari found in Indian cattle are proved identical with $H b-C$ and $H b-D$ of African cattle, then we could think of a common ancestry for Asiatic and African zebu. The other explanation for the occurrence of these rare variants could be independent mutation in India and Africa, when the possessor might enjoy some selective advantage over 
other types. These rare variants, though not associated with any clinical symptoms, are of great anthropological and evolutionary interest.

The quantitative study of the haemoglobin variants in the heterozygotes provide interesting genetic examples of dosage effects. The alleles concerned have an equal efficiency in the synthesis of haemoglobin quantities, but the differences in their electrophoretic mobility prove the existence of molecular differences. The studies of Efremov and Braend (1965) have shown that $H b-A, H b-B, H b-C, H b-D$ and $H b-F$ have a common slow moving polypeptide chain, while the fast moving chains differed from one another. Balani and Barnabas (1964) also reported similar findings with regard to $H b-A$ and $H b-B$. Sukumaran (1965), in a preliminary study of $H b-A$ and $H b-B$ of Indian cattle, showed some apparent differences in the amounts of some aminoacids of the two globins, by determining their total aminoacid composition. Peptide analyses on the tryptic digests, in his study, showed no difference in the aminoacid sequence of $20 \alpha$ - and $20 \beta$-peptides, in the two haemoglobins. Comparison of these peptides with that of human haemoglobin showed no differences in the $20 \beta$-peptides while replacement of lysine by an alanine was noticed in $20 \alpha$-peptide in cattle haemoglobin. Schroeder et al. (1967), in a comparative study of amino acid sequence in the $\alpha$ - and $\beta$-chains of adult bovine $H b-A, H b-B$, showed no difference in their $\alpha$-chains while there were multiple differences in $\beta$-chains involving substitution in $T p-2$ at 15 (Gly $\ldots \rightarrow \rightarrow$ Ser); Tp-3a at 18 (Lys $\ldots \rightarrow$ His) and $T p-14 a$ at 119 (Lys $-\cdots \rightarrow$ Asn). These preliminary studies have shown the existence of differences in the amino acid sequence of $\beta$-chains of $H b-A$ and $H b-B$. With the discovery of four adult haemoglobin variants in cattle and with the advancement of modern techniques it seems that there is great scope for further work to demonstrate the exact differences in the amino acid composition and/or their sequence in both $\alpha$ - and $\beta$-chains of bovine haemoglobins.

\section{Summary}

1. Haemoglobin variants were studied in $2158 \mathrm{zebu}$ cattle belonging to 7 Indian breeds and compared with those in Jersey, Bohemian Red Spotted and Finnish cattle.

2. Two new variants called $H b-X$ and $H b$-Khillari, besides the common $H b-A$ and $H b-B$, were detected.

3. The significance of the variations in the occurrence and geographical distribution of haemoglobin types is discussed in the light of the physiological adaptability and origin of the cattle breeds.

Acknowledgment.-Our grateful thanks are due to the authorities of Cattle Breeding Farm, Kandivali; Aadarsha Dugdhalaya, Malad, Bombay, and Dr D. R. Chavan, Chief Animal Husbandry Officer, Aarey Milk Colony, Bombay, and Dr S. A. Malandkar, i/c Bandra Slaughter House, for their co-operation and permission to collect blood samples from the cattle. Our thanks are also due to the European Society for Animal Blood Group Research, and Dr J. Matousek of Czechoslovakia and Dr Gunvor Lindstrom of Finland for the cattle blood samples, the haemoglobin variants of which are compared. We are also thankful to Dr P. Bhattacharya, the Animal Husbandry Commissioner with the Government of India; Dr S. S. Prabhu, Chief of the Genetics Division and Dr G. L. Sharma, Chief of the Pathology Division of Indian Veterinary Research Institute, India, for their kind co-operation in supplying blood samples from the hill cattle. We express our grateful appreciation to Dr A. E. Mourant, Director, Serological Population Genetics Laboratory, London, for critically going through the manuscript. 


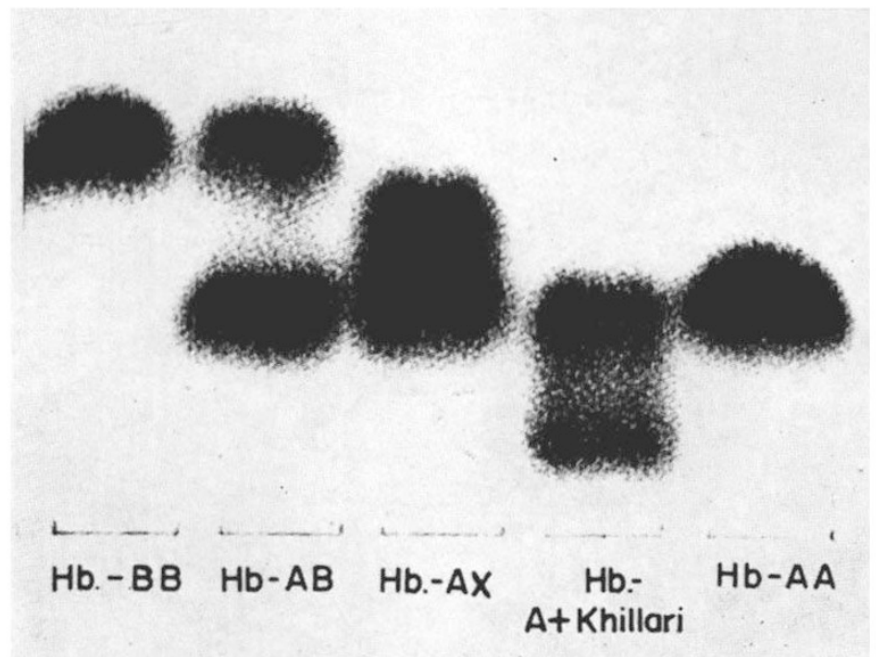

Plate Ia.-Haemoglobin variant in the zebu cattle. (Paper Electrophoresis Veronal Buffer $p \mathrm{H} \mathrm{8.6.)}$

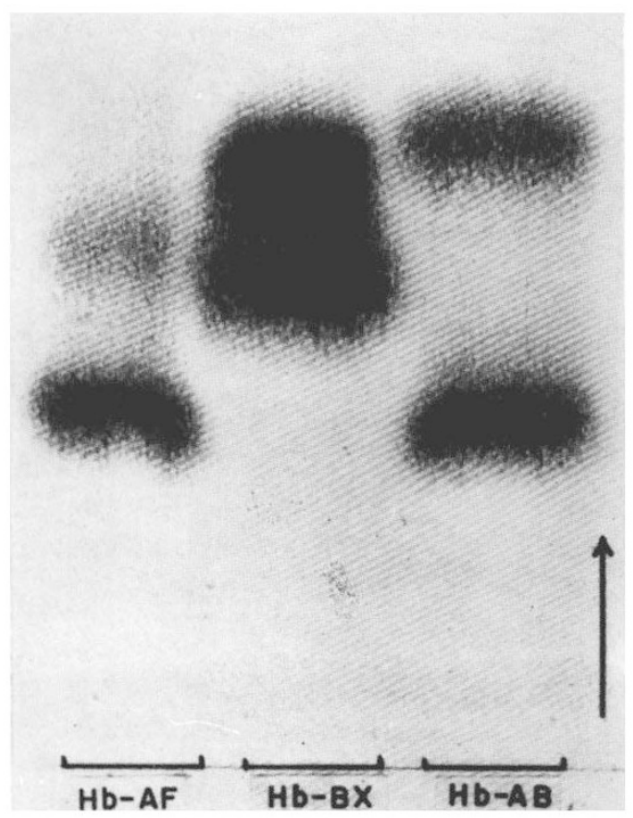

Plate $I b$.--Papcr elcctrophoretic pattern showing comparative mobilities of $H b-A+$ Foctal; $H b-B X$ and $H b-A B$ (Veronal Buffer $p \mathrm{H} 8 \cdot 6$.) 


\section{REFERENCES}

ALlison, A. C. 1954. Protection afforded by sickle-cell trait against subtertian malarial infection. Brit. med. J., 1, 290-294.

BALANI, A. S., AND BARNABAS, J. 1964. Evaluation of multiple haemoglobins of ruminants by tryptic peptide pattern analysis. Ind. J. Biochem., 1, 220-224.

BALAKRISHNAN, C. R., AND NAIR, P. G. 1966. Haemoglobin polymorphism in Indian cattle. Ind. 7. Genet., 26-A, 374-385.

BANGHAM, A. D. 1957. Distribution of electrophoretically different haemoglobins among cattle breeds of Great Britain. Nature, Lond., 179, 467-468.

BANGHAM, A. D., AND BLUMBERG, B. s. 1958. Distribution of electrophoretically different haemoglobins among some cattle breeds of Europe and Africa. Nature, Lond., 181, 1551-1552.

CABANNES, R., AND SERAIN, C. 1957. Etude electrophorétique des hémoglobines des Mammiferes domestiques d'Algérie. C.R. So6. Biol., Paris, 149, 1193.

CARr, w. R. 1965. A new bovine haemoglobin variant. Rhod. J. Agric. Res., 3, 62.

CROCKETT, J. R., KOGER, M., AND CHAPMAN, H. L. 1963. Genetic variation in haemoglobins of beef cattle. 7. Anim. Sci., 22, 173-176.

EFREMOV, G., AND BRAEND, M. 1965. Differences in cattle globins. Biochem. J., 97, 867-869.

EVANS, J. V., HARRIS, H., AND WARREN, F. L. 1957. Haemoglobin types in British breeds of sheep. Biockem. 7., 65, 42.

GRIMES, R. M., DUNCAN, C. W., AND LASSITER, C. A. 1957. Occurrence of multiple haemoglobin in certain breeds of dairy cattle. F. Dairy Sci., 40, 1338-1342.

KIDDY, C. A. 1964. Inherited differences in specific blood and milk proteins in cattle: a review. 7. Dairy Sci., 47, 510-515.

LEHMANN, H. 1959. The haemoglobins of 103 Indian Gir cattle. Man, No. 91.

LEHMANN, H., AND Ross, J. G. 1961. Haemoglobin phenotypes in Nigerian cattle. Man, No. 101 .

MOORE, S. L., GODLEY, W. C., G. VAN VLIET., LEWIS, J. P., BOYD, E., AND HUISMAN, T. H. J. 1966. The production of $H b-C$ in sheep carrying gene for $H b-A$ : haematological aspects. Blood, 28, 314-329.

Naik, s. N., sukumaran, P. K., AND Sanghvi, L. D. 1962. Communicated to and quoted by Crockett et al. (1963).

NAIK, s. N., sukumaran, P. K., AND SANGhvi, L. D. 1965. A note on blood groups and haemoglobin variants in zebu cattle. Animal Production, 7, 275-277.

NAIK, s. N., AND SANGHVI, L. D. 1964. A new haemoglobin variant in zebu cattle. Paper presented at the 9th European Animal Blood Group Conference, Prague, August 1964.

ogden, A. L. 1961. Biochemical polymorphism in farm animals. Anim. Breed. Abst., 29, 127-138.

SALIBSURY, G. W., AND SHREFFleR, D. C. 1957. Haemoglobin variants in dairy cattle. $\mathcal{J}$. Dairy Sci., 40, 1198.

SCHROEDER, W. A., SHELTON, J. R., SHELTON, J. B., ROBBERSON, B., AND BABIN, D. R. 1967. A comparison of aminoacid sequences in the $\beta$-chains of adult bovine haemoglobins $\mathrm{A}$ and B. Archives of Biochem. E' Biophys., 120, 124-135.

SEN, A. ROY, DEBDUtTA, BHATTACHARYA, S., AND DEB, N. C. 1966. Haemoglobin of Indian zebu cattle and the Indian Buffalo. Animal Sci., 25, 445-448.

SHREFFLER, D. C., AND SALISBURY, G. W. 1959. Distribution and inheritance of haemoglobin variants in American cattle. 7. Dairy Sci., 42, 1147-1156.

sukumaran, P. K. 1965. Studies on the haemoglobins $A$ and $B$ of Indian cattle. Biochim. Biophys. Acta., 100, 616-618. 